\title{
Daños colaterales. Desigualdades sociales en la era global*
}

\author{
Zygmunt Bauman
}

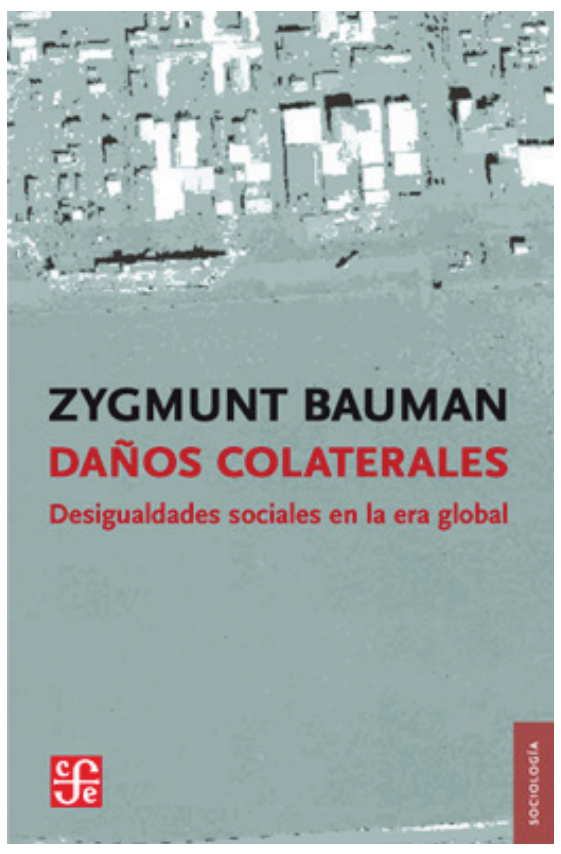

MAXIMILIANO KORSTANJE

Daños colaterales, una obra estrenada hace un par de años por Zygmunt Bauman, sintetiza no sólo parte de su carrera profesional e intelectual, sino que pone el foco en las asimetrías causadas por el capitalismo avanzado, al cual el autor bautiza como modernidad líquida. Particularmente, la tesis central del trabajo de Bauman discute los alcances y los resultados

2012. Buenos Aires: Fondo de Cultura Económica. 232 páginas.

** Universidad de Palermo, Argentina. Correo electrónico: maxikorstanje@arnet.com.ar 
de una gran desigualdad entre los que tienen y los que no. En parte, porque el estado nacional como protector de la ciudadanía, o como aquel organismo funcional a la seguridad general, dio paso a una nueva forma de estado, en donde lo social impone los riesgos y/o peligros que las personas deben afrontar en forma individual.

En esta verdadera brecha que se da entre oikos (mundo privado) y Ekklesia (espacio público), el mercado acude a prestar sus servicios a una ciudadanía que se ha transformado en un segmento de consumidores. La gestión del ciudadano para mitigar los riesgos creados por el sistema social sugiere la contratación de diferentes productos que van desde seguros hasta dispositivos de control y vigilancia. Bauman explica que, indudablemente, el comunismo ha jugado un rol importante en la crítica del estado moderno racional, ya sea por el sentido de la explotación o por el miedo a la pobreza siempre presente. No obstante, estas críticas dieron lugar al nacimiento de un estado organizado para explotar el deseo individual, liberando los márgenes para crear una sociedad de consumo.

Si en el mundo moderno el peligro estaba controlado por medio de la técnica, en la sociedad de la modernidad líquida, la incertidumbre y el temor se han convertido en los dos pilares discursivos que llevan a la elite a mantener su poder. El desastre sólo hace el trabajo de reciclaje (renovación) de la mano de obra mucho más sencillo. No sólo el comunismo ha sido fútil para revertir los efectos nocivos del capitalismo, sino que ha coadyuvado para la concreción de una forma más perversa de dominación.

Siguiendo este argumento, Bauman cita el trabajo de Michel Crozier (1964) quien, a mediados de siglo XX, publicaba una obra titulada The bureaucratic phenomenon, donde ejerce una crítica radical contra Max Weber. A diferencia de la burocracia alemana, centrada en un ethos racional, Crozier observa un escenario en ciento ochenta grados. Los grupos directivos no sólo usan la incertidumbre para generar caos y descontrol, sino que se aprovechan de la confusión para controlar a la masa laboral. Esta observación inspira a Bauman a confirmar que Crozier fue el primer erudito francés en descubrir el axioma de la incertidumbre que Weber ignoró. Específicamente, ésta asume que quienes se encuentran cercanos al origen de la incertidumbre se alzan con el poder y el control de una organización social. ¿De qué manera podemos afirmar esto? Las personas en la organización observada por Crozier utilizan y siguen las reglas según sus propias conveniencias, alterando no sólo la 
línea de autoridad, sino que aprovechando las lagunas en los estatutos legales. Bauman agrega:

Dicha estrategia, como lo aprendí de Crozier, consiste, en todos los tiempos y en todas partes, en la manipulación de la inseguridad. La incertidumbre, causa principal de la inseguridad, es por lejos el más decisivo instrumento de poder: de hecho, es su propia sustancia. Tal como lo anuncia Crozier, quienes están cerca de las fuentes de incertidumbre son quienes ejercen el dominio (p. 61).

Esta cita es de capital importancia para estructurar toda la teoría baumaniana, en particular, su concepción del miedo como instrumento de la política coercitiva. En la modernidad líquida la elite sienta las bases para generar movilidad, libertad y progreso en un sentido del péndulo mientras, en el opuesto, la base de producción queda inmovilizada, controlada, sujeta a padecer riesgos creados por otras partes de la sociedad. Paradójicamente, el otro que habitaba en la multiplicidad de las grandes ciudades, comienza a ser concebido como un "otropeligroso" que opta por habitar en un espacio en el cual no es bienvenido. Sin embargo, estos espacios de aislamiento total generan efectos no deseados, ya que disminuye la tolerancia que cada uno de nosotros tiene por los otros. Cuando las murallas de estas fortalezas -que en Latinoamérica se conocen como barrios cerrados- se sortean, la angustia radical florece. Ello sucede debido a que la "obsesión por la seguridad" (p. 99) se encuentra condenada a la socavación de la reciprocidad y la confianza.

El libro se encuentra estructurado para discutir tres ejes filosóficos bien distintos pero interconectados, seguramente atendiendo a lo que Bauman ha llamado "la modernidad líquida":

a) La concepción política del otro frente a la incertidumbre (capítulos I, II, III y IV).

b) El declive moral del consumismo moderno y la objetivación del ciudadano en commodity (capítulos V, VI, VII y VIII).

c) El origen del mal como condición de la normalidad humana, o lo que Arendt (1963) llamara banalidad del mal. La monstruosidad no nace de quienes hacen actos monstruosos, sino de quienes sacrifican su capacidad crítica (capítulos IX, X y XI).

Aun cuando breve en el número de páginas, Daños colaterales ofrece un profundo andamiaje sociológico respecto de la sociedad postmoderna, el darwinismo social, la idea de hospitalidad y extranjería, como así 
también la manera en que los dilemas éticos llevan a falsas soluciones. La radicalización del otro admite que debamos quitarle su identidad, y sin ella, es mucho más simple reducirlo o exterminarlo a nada. Bauman pone en el ojo de la crítica, una vez más, dos aspectos del capitalismo moderno que merecen ser discutidos. El primero y más importante es el rol del temor como un instrumento de adoctrinamiento político que lleva a formas sesgadas de democracia, pero además su aleatoriedad (es decir, que cualquier persona puede ser alcanzada por cualquier riesgo en cualquier momento) pone al ciudadano de espaldas a su propia capacidad crítica. Segundo, el alarmismo lleva directamente al desastre total pues las diversas barreras de control se anulan. En lugar de corregir aquellos errores que generan desastres, afianzamos más la lógica de exclusión con el fin de que esos cataclismos hagan una purga en toda una "infra clase" que es disfuncional al sistema de consumo.

Hasta aquí hemos discutido el argumento del profesor Bauman con el fin de dar al lector una guía clara de sus axiomas, tesis e ideas principales. No obstante, existe en su propia concepción de la hospitalidad un problema conceptual importante. Los hombres, desde antaño, han conferido hospitalidad a los extranjeros como signo de devoción para ser ellos mismos protegidos en el más allá en el último de sus viajes. En las tribus europeas antiguas, los desastres naturales, las hambrunas y las plagas eran el resultado directo de la falta de hospitalidad hacia los extraños. Sociológicamente, ello tiene una explicación. Los hombres hacen con los extraños lo que luego estarán en condiciones de solicitar a los dioses. Empero, una vez muerto Dios, y muerta la religión, la sociedad postmoderna no tiene razones para valorar, menos para proteger, a los extranjeros (Korstanje 2015a).

Por un lado, el argumento de Bauman muestra ciertas falencias para comprender esta relación, que después de todo es antro-filosófica. Por otro lado, el capitalismo postmoderno muestra evidencia sustancial de un grado de polarización producto de que, como bien observa Bauman, pocos tienen mucho y muchos acceden a poco. Sin embargo, esta dialéctica se encuentra previamente determinada por el sentido anglosajón y protestante de la predestinación, como bien demostráramos en A difficult world: Examining the roots of capitalism (Korstanje 2015b), la desigualdad es la consecuencia de la metáfora o las estructuras mitológicas como el Libro de la vida (Book of life) o el Arca de Noé, donde un grupo selecto de almas se gana el derecho a la salvación eterna mientras el resto de la humanidad perece. 
El capitalismo ha sabido construir, en base a estos dos mitos, un andamiaje económico de la exclusión, donde la incertidumbre no deriva de la falta de confianza, sino del darwinismo social en donde todos compiten con todos para alcanzar la bendición divina. $Y$ es, entonces, que confiados de sus habilidades personales, ninguno de los competidores -como los trabajadores- son conscientes de su amargo final o, mejor dicho, de su inevitable precarización. Ideológicamente, y a diferencia de los Juegos Olímpicos donde hay una multiplicidad de ganadores, esta idea de la salvación es lo que propugna el campeonato FIFA de fútbol, en el cual 64 selecciones tienen muy pocas probabilidades de ganar, de hecho sólo una lo hará, empero todas ellas entran en competencia porque ignoran las verdaderas reglas del juego (Korstanje, Tzanelli y Clayton 2014).

\section{Bibliografía}

Arendt, H. 1963. Eichmann in Jerusalem. New York: Penguin.

Crozier, M. 1964. The bureaucratic phenomenon. London: Tavistoc.

Korstanje, M. 2015a. "Reviewing the concept of hospitality in a contemporary world". En línea, disponible en: http://cers.leeds.ac.uk/files/2015/06/Korstanje_CERS_6.pdf 2015b. A difficult world: Examining the roots of capitalism. New York: Nova Science Publishers.

, Tzanelli, R. y Clayton, A. 2014. "Brazilian World Cup 2014: Terrorism, tourism, and social conflict". Event Management 18 (4): 487-491. 
